\title{
CRYSTAL STRUCTURE OF $\mathrm{K}_{3} \mathrm{Na}\left(\mathrm{SeO}_{4}\right)_{2}$ AT $340 \mathrm{~K}$
}

\author{
T. FUKAMI* \\ Department of Physics and Earth Sciences, Faculty of Science \\ University of the Ryukyus, Okinawa 903-0213, Japan \\ AND R.H. CHEN \\ Department of Physics, National Taiwan Normal University \\ Taipei, Taiwan, 117, Republic of China \\ (Received July 14, 1998; in final form October 12, 1998)
}

\begin{abstract}
The crystal structure of tripotassium sodium diselenate, $\mathrm{K}_{3} \mathrm{Na}\left(\mathrm{SeO}_{4}\right)_{2}$, at $340 \mathrm{~K}$ is studied by single-crystal $\mathrm{X}$-ray diffraction. The space group symmetry (trigonal $P \overline{3}$ ) and structure parameters are determined. It is found that there exists the difference of the direction and the magnitude of the atomic displacement at the two phase transitions of $346 \mathrm{~K}$ and $334 \mathrm{~K}$.
\end{abstract}

PACS numbers: $61.66 . F n, 64.60 . \mathrm{Fr}$

\section{Introduction}

Tripotassium sodium diselenate, $\mathrm{K}_{3} \mathrm{Na}\left(\mathrm{SeO}_{4}\right)_{2}$, crystal is a member of a family which can be described by chemical formula $\mathrm{A}_{3} \mathrm{C}\left(\mathrm{BX}_{4}\right)_{2}$, where $\mathrm{A}, \mathrm{C}=$ $\mathrm{Na}, \mathrm{K}, \mathrm{Rb}$ and $\mathrm{BX}_{4}=\mathrm{SO}_{4}, \mathrm{SeO}_{4}, \mathrm{CrO}_{4}, \mathrm{MoO}_{4}$ [1]. It undergoes several successive structural phase transitions above the room temperature: the melting point at $1170 \mathrm{~K}$, two high-temperature phase transitions at $758 \mathrm{~K}$ and $730 \mathrm{~K}$, and two low-temperature phase transitions at $346 \mathrm{~K}$ and $334 \mathrm{~K}[2,3]$. The low-temperature structural transitions are detected by a set of independent experiments. The former is accompanied by the anomalies as measured in differential thermal analysis (DTA) curves, thermal expansions, and dielectric constants. The structural phase transition at $334 \mathrm{~K}$ is deduced from the temperature dependence of the elastic constants [2-4]. Furthermore, it is determined from the studies of Brillouin shifts that the elastic constant $c_{33}$ exhibits anomalous behavior at $346 \mathrm{~K}$, and $c_{44}$ has two minima at $334 \mathrm{~K}$ and $346 \mathrm{~K}$ [5]. It is shown that the sample crystal exhibits ferroelastic properties at room temperature. The ferroelastic character of the relevant transition is concluded from the observation of domain structure in the polarized light and the domains which are reorientable under the external force are clearly observed below $334 \mathrm{~K}$ [6]. Recently, the symmetry of the sample crystal in the intermediate phase $(334-346 \mathrm{~K})$ has been determined to be trigonal with the point group $\overline{3}$ in the Raman scattering measurements [7].

The crystal structure of $\mathrm{K}_{3} \mathrm{Na}\left(\mathrm{SeO}_{4}\right)_{2}$ at $390 \mathrm{~K}$ has been determined to be trigonal $P \overline{3} m 1$ with the lattice parameters: $a=5.906(3)$ and $c=7.552(1) \AA$, and there is one molecule in a unit cell. The crystal structure at $291 \mathrm{~K}$ was determined

\footnotetext{
*e-mail: fukami@gen.u-ryukyu.ac.jp
} 
with the assumption that the observed X-ray intensities are overlapped by the reflections from the three domains. The determined structure at $291 \mathrm{~K}$ is monoclinic $C 2 / c$ and the cell parameters are $a=10.162(2), b=5.867(1), c=15.021(2) \AA$ and $\beta=90.00(1)^{\circ}$. There are four molecules in a unit cell [8].

However, the structure of the sample crystal between $334 \mathrm{~K}$ and $346 \mathrm{~K}$ has not been reported yet. The purpose of this paper is to determine the crystal structure of $\mathrm{K}_{3} \mathrm{Na}\left(\mathrm{SeO}_{4}\right)_{2}$ in this temperature range, and to discuss the details of its phase transitions.

\section{Experimental}

The sample crystal of $\mathrm{K}_{3} \mathrm{Na}\left(\mathrm{SeO}_{4}\right)_{2}$ were grown at room temperature by slow evaporation from aqueous solutions containing $\mathrm{K}_{2} \mathrm{SeO}_{4}$ and $\mathrm{Na}_{2} \mathrm{SeO}_{4}$ in the molar ratio of $3: 1$. The obtained crystals are in the form of hexagonal $c$-plates. The $\mathrm{X}$-ray measurement was carried out by using an Enraf-Nonius CAD-4 four-circle automatic diffractometer with an express software and graphite monochromated Mo $K_{\alpha}$ radiation $(\lambda=0.71073 \AA)$. The sample temperature was controlled by using heated $\mathrm{N}_{2}$ gas with a low-temperature apparatus (FR558SH) of Enraf-Nonius, and the temperature fluctuations were kept within $\pm 0.5 \mathrm{~K}$. The observed profiles of the X-ray reflection of the sample crystal at $340 \mathrm{~K}$ showed a single peak on the graphic display. Therefore, the sample crystal was considered to be mono-domain. Crystal data and the experimental conditions are listed in Table I. The inten-

\section{TABLE I}

Crystal data, data collection, and structure refinement.

\begin{tabular}{l|l}
\hline \multicolumn{2}{c}{ Crystal data } \\
\hline Compound & $\mathrm{K}_{3} \mathrm{Na}\left(\mathrm{SeO}_{4}\right)_{2}$ \\
Chemical formula weight & $M_{\mathrm{r}}=426.21$ \\
Crystal system & Trigonal \\
Space group & $P \overline{3}$ \\
Lattice constants & $a=5.8725(5) \AA$ \\
& $c=7.5092(8) \AA$ \\
Volume of unit cell & $V=224.27(7) \AA^{3}$ \\
Formula unit per cell & $Z=1$ \\
Density calculated from formula and cell & $D_{x}=3.156 \mathrm{~g} \mathrm{~cm}^{-3}$ \\
Number of reflections for cell measurement & 25 \\
$\theta$ range for cell measurement & $\theta=21.0-24.7^{\circ}$ \\
Linear absorption coefficient & $\mu=96.13 \mathrm{~cm}{ }^{-1}$ \\
Measurement of temperature & $T=340.0 \pm 0.5 \mathrm{~K}$ \\
Crystal shape & Hexagonal plate \\
Crystal color & Colorless \\
Sample shape & Sphere \\
Sample size in diameter & $2 r=0.028 \mathrm{~cm}$
\end{tabular}


TABLE I (cont.)

\begin{tabular}{l|l}
\hline \hline \multicolumn{2}{c}{ Data collection } \\
\hline Data-collection method & $\omega / 2 \theta$ scans \\
Absorption correction type & Spherical \\
Number of reflections measured & 3837 \\
Number of independent reflections & 1289 \\
Maximum value of $\theta$ & $\theta_{\max }=44.95^{\circ}$ \\
Range of $h, k$ and $l$ for measured intensities & $h=-11 \rightarrow 11$ \\
& $k=-11 \rightarrow 11$ \\
Number of standard reflections & $l=-14 \rightarrow 0$ \\
Interval time & 3 \\
Intensity decay & 120 min \\
\hline \multicolumn{1}{c}{ Refinement } & $-2.06 \%$ \\
\hline Refinement on $F$ & \\
$R$ factor & $R=0.0183$ \\
$w R$ factor & $w R=0.0227$ \\
Goodness of fit & $S=0.554$ \\
Number of reflections used in refinement & 795 \\
Criterion for reflections & $I>3 \sigma(I)$ \\
Number of parameters refined & 24 \\
Equivalent reflections & $R_{\text {int }}=0.057$ \\
Weighting scheme & $w=1 /\left[\sigma^{2}(F)+(0.02 F)^{2}+1.0\right]$ \\
Maximum of shift/esd & $(\Delta / \sigma)_{\max }=0.026$ \\
Maximum of difference density & $\Delta \rho_{\max }=0.615 \mathrm{e} \AA^{-3}$ \\
Minimum of difference density & $\Delta \rho_{\min }=0.0 \mathrm{e} \AA^{-3}$ \\
Extinction coefficient & $0.85(1) \times 10^{-5}$ \\
& \\
& \\
&
\end{tabular}

sity data were corrected for both Lorentz-polarization and absorption effects. The structure was refined by the full-matrix least-squares method using a MolEN crystallographic software package with a VAX 4000 station, and all atoms were refined with anisotropic thermal parameters.

\section{Results and discussion}

Figure 1 shows the temperature dependence of the four measured intensities of X-ray reflections indexed with pseudohexagonal $\mathrm{K}_{3} \mathrm{Na}\left(\mathrm{SeO}_{4}\right)_{2}$ on heating. The long measuring time is taken for $\omega / 2 \theta$ scan $(2.06 \mathrm{degree} / \mathrm{min})$. These four reflections have the strong intensity as chosen from all reflections with the $l$ odd. It is found that the intensity of the four reflections decreases almost along the straight lines with increasing temperature but the slope of the line turns into the same at about $340 \mathrm{~K}$. These four strong reflections and the other reflections with the $l$ 
odd disappeared at about $350 \mathrm{~K}$. The obtained temperatures for the change of the slope and the disappearance of the chosen reflections are in good agreement with the phase transition temperatures as previously reported $[2,3]$.

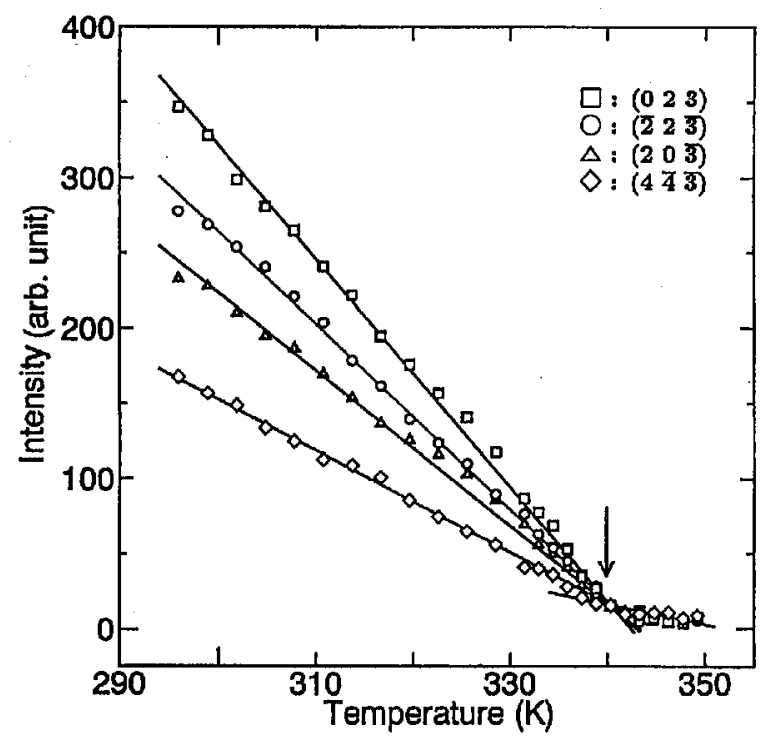

Fig. 1. Temperature dependence of four X-ray reflection intensities of pseudohexagonal $\mathrm{K}_{3} \mathrm{Na}\left(\mathrm{SeO}_{4}\right)_{2}$ on heating. The change of the slope of the lines is indicated by an arrow.

The crystal structure of $\mathrm{K}_{3} \mathrm{Na}\left(\mathrm{SeO}_{4}\right)_{2}$ at $340 \mathrm{~K}$ was analyzed by $\mathrm{X}$-ray diffraction. The intensities of the all reflections with odd $l$ as shown in Fig. 1 were very weak and were not detected by an usual method of the X-ray measurements. Then, the lattice parameter along the $c$-axis at $340 \mathrm{~K}$ was determined to be a half of that of the room-temperature phase. The observed systematic extinction of the $\mathrm{X}$-ray reflection reveals that the possible space groups are $P \overline{3} m 1, P 3 m 1, P 321, P \overline{3} 1 m, P 31 m, P 312, P \overline{3}$, and $P 3$. By the comparison of the equivalent reflections, it indicated that the Laue class of the sample crystal is $\overline{3}$. Then, the space group is considered to be $P \overline{3}$ or $P 3$. This result is in agreement with the study from the Raman scattering [7]. In the preliminary structure analysis with an isotropic thermal parameter, the discrepancy factors ( $R$ factors) calculated for the above space groups are reduced to about 0.07 . But the number of free parameters refined for $P 3$ is about twice as many as that for $P \overline{3}$. Therefore, the space group $P 3$ can be readily discarded with only a slightly better $R$ factor, and the space group $P \overline{3}$ is chosen with the only possible. The final $R$ factor was reduced to 0.0183 .

Figure 2 shows the obtained crystal structure at $340 \mathrm{~K}$. The positional parameters in fractions of a unit cell and the thermal parameters are listed in Table II. The bond lengths in $\AA$ and the bond angles in degree are given in Table III. Comparing the obtained fractions of the positional parameters of $340 \mathrm{~K}$ with those of $390 \mathrm{~K}$, it is found that the $\mathrm{O}(2)$ atom deviates from the site symmetry of mirror 


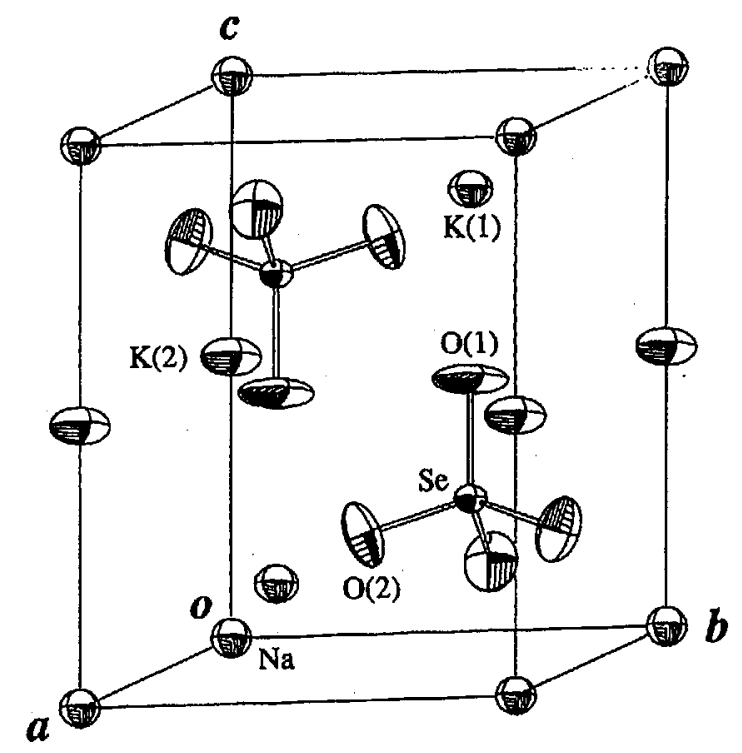

Fig. 2. Crystal structure of $\mathrm{K}_{3} \mathrm{Na}\left(\mathrm{SeO}_{4}\right)_{2}$ at $340 \mathrm{~K}$ with $70 \%$-probability-displacement ellipsoids.

TABLE II

Positional parameters in fractions of a unit cell and thermal parameters $\left(\times 10^{-4} \AA^{2}\right)$ at $340 \mathrm{~K}$. The anisotropic thermal parameters are defined as $\exp \left[-2 \pi^{2}\left(U_{11} a^{* 2} h^{2}+\right.\right.$ $\left.\left.U_{22} b^{* 2} k^{2}+U_{33} c^{* 2} l^{2}+2 U_{12} a^{*} b^{*} h k+2 U_{13} a^{*} c^{*} h l+2 U_{23} b^{*} c^{*} k l\right)\right]$.

\begin{tabular}{c|c|c|c|c|c|c|c|c|c}
\hline \hline Atom & $X$ & $Y$ & $Z$ & $U_{11}$ & $U_{22}$ & $U_{33}$ & $U_{12}$ & $U_{13}$ & $U_{23}$ \\
\hline $\mathrm{Se}$ & $1 / 3$ & $2 / 3$ & $0.27407(3)$ & $131.3(4)$ & $131.3(4)$ & $86.6(5)$ & $65.7(2)$ & 0 & 0 \\
$\mathrm{~K}(1)$ & $1 / 3$ & $2 / 3$ & $0.82736(7)$ & $227(1)$ & $227(1)$ & $156(1)$ & $113(1)$ & 0 & 0 \\
$\mathrm{~K}(2)$ & 0 & 0 & $1 / 2$ & $432(3)$ & $432(3)$ & $164(3)$ & $216(2)$ & 0 & 0 \\
$\mathrm{Na}$ & 0 & 0 & 0 & $187(3)$ & $187(3)$ & $172(5)$ & $93(2)$ & 0 & 0 \\
$\mathrm{O}(1)$ & $1 / 3$ & $2 / 3$ & $0.4884(3)$ & $694(13)$ & $694(13)$ & $88(6)$ & $347(7)$ & 0 & 0 \\
$\mathrm{O}(2)$ & $0.1835(2)$ & $0.3666(2)$ & $0.1968(2)$ & $300(4)$ & $189(3)$ & $461(6)$ & $94(3)$ & $-76(5)$ & $-152(4)$
\end{tabular}

plane ( 0.0007 along the $a$-direction and 0.0019 along the $b$-direction) in the phase at $340 \mathrm{~K}$. It changes the space group symmetry from $P \overline{3} m 1$ to $P \overline{3}$. The observed $\mathrm{SeO}_{4}$ tetrahedra are slightly distorted from ideal tetrahedra in all three phases. The bond distances between the Se and $\mathrm{O}$ atoms are slightly decreasing with the increasing temperature.

Table IV shows the displacement of the atoms as the temperature changes from $390 \mathrm{~K}$ to $340 \mathrm{~K}$ and from $340 \mathrm{~K}$ to $291 \mathrm{~K}$. It is found that all atoms shift to the negative direction of the $a$ - and $b$-axes with the ratio about $1: 2$ as the temperature is lowered from $390 \mathrm{~K}$ to $340 \mathrm{~K}$. That is, the displacement of the atoms is about $0.11 \AA$ along the negative direction of the $b$-axis. From $340 \mathrm{~K}$ to $291 \mathrm{~K}$, the $\mathrm{O}(1)$ atom shifts to the positive directions of the $a$ - and $b$-axes while the Se and $O(2)$ atoms shift to the negative directions of the $a$ - and $b$-axes with the even larger ratios. The displacements of the atoms from $340 \mathrm{~K}$ to $291 \mathrm{~K}$ are 
TABLE III

Bond lengths in $\AA$ and bond angles in degrees at $340 \mathrm{~K}$.

\begin{tabular}{l|l|l|l}
\hline \hline \multicolumn{4}{c}{ Bond lengths } \\
\hline $\mathrm{Se}-\mathrm{O}(1)$ & $1.609(2)$ & $\mathrm{Se}-\mathrm{O}(2)$ & $1.632(1)$ \\
$\mathrm{O}(1)-\mathrm{O}(1)^{a}$ & $3.3950(2)$ & $\mathrm{O}(1)-\mathrm{O}(2)^{a}$ & $3.773(2)$ \\
$\mathrm{O}(1)-\mathrm{O}(2)$ & $2.668(2)$ & $\mathrm{O}(2)-\mathrm{O}(2)^{b}$ & $2.643(2)$ \\
$\mathrm{O}(2)-\mathrm{O}(2)^{c}$ & $3.230(2)$ & $\mathrm{O}(2)-\mathrm{O}(2)^{d}$ & $3.495(2)$ \\
$\mathrm{K}(1)-\mathrm{O}(1)$ & $2.546(2)$ & $\mathrm{K}(1)-\mathrm{O}(2)^{a}$ & $2.947(2)$ \\
$\mathrm{K}(1)-\mathrm{O}(2)^{e}$ & $3.166(2)$ & $\mathrm{K}(2)-\mathrm{O}(2)$ & $2.943(1)$ \\
$\mathrm{Na}-\mathrm{O}(2)$ & $2.379(1)$ & $\mathrm{Na}-\mathrm{K}(1)^{a}$ & $3.6299(2)$ \\
\hline \multicolumn{4}{|c}{$\mathrm{Bond}$ angles } \\
\hline $\mathrm{O}(1)-\mathrm{Se}-\mathrm{O}(2)$ & $110.81(6)$ & $\mathrm{O}(2)-\mathrm{Se}-\mathrm{O}(2)$ & $108.10(8)$ \\
\hline${ }^{a} y, y-x, 1-z ;{ }^{b} 1-y, 1+x-y, z ;$ \\
${ }^{c} y-x,-x, z ;{ }^{d} y, y-x,-z ;{ }^{e} x, y, 1+z$ \\
\hline
\end{tabular}

TABLE IV

Displacements $(\AA)$ of the atom positions (a) from $390 \mathrm{~K}$ to $340 \mathrm{~K}$ and (b) from $340 \mathrm{~K}$ to $291 \mathrm{~K}$ with the trigonal axis.

\begin{tabular}{l|l|l|l}
\hline \multicolumn{4}{c}{ (a) From $390 \mathrm{~K} \rightarrow 340 \mathrm{~K}$} \\
\hline Atoms & \multicolumn{1}{|c}{$x$} & \multicolumn{1}{c}{$y$} & \multicolumn{1}{c}{$z$} \\
\hline$\Delta \mathrm{Se}$ & -0.0112 & -0.0223 & $0.0008(5)$ \\
$\Delta \mathrm{K}(1)$ & -0.0112 & -0.0223 & $-0.010(1)$ \\
$\Delta \mathrm{K}(2)$ & 0 & 0 & -0.0214 \\
$\Delta \mathrm{O}(1)$ & -0.0112 & -0.0223 & $0.003(6)$ \\
$\Delta \mathrm{O}(2)^{a}$ & $-0.013(2)$ & $-0.023(2)$ & $-0.006(4)$ \\
$\Delta \mathrm{O}(2)$ & $-0.010(2)$ & $-0.023(3)$ & $-0.006(4)$ \\
$\Delta \mathrm{O}(2)^{b}$ & $-0.010(3)$ & $-0.021(2)$ & $-0.006(4)$ \\
\hline \multicolumn{5}{|c}{$(\mathrm{b})$ From $340 \mathrm{~K} \rightarrow 291 \mathrm{~K}$} \\
\hline$\Delta \mathrm{Se}$ & $-0.0136(6)$ & $-0.1682(2)$ & $-0.0039(4)$ \\
$\Delta \mathrm{K}(1)$ & $0.015(1)$ & $-0.1764(4)$ & $-0.0102(5)$ \\
$\Delta \mathrm{K}(2)$ & 0 & $-0.1621(5)$ & 0.00065 \\
$\Delta \mathrm{O}(1)$ & $0.0475(8)$ & $0.065(2)$ & $-0.011(4)$ \\
$\Delta \mathrm{O}(2)$ & $-0.015(4)$ & $-0.177(4)$ & $-0.135(5)$ \\
$\Delta \mathrm{O}(3)$ & $-0.027(5)$ & $-0.175(4)$ & $0.153(5)$ \\
$\Delta \mathrm{O}(4)$ & $-0.023(6)$ & $-0.121(4)$ & $-0.027(8)$ \\
\hline$a y-x,-x, z ;{ }^{b}-y, x-y, z$
\end{tabular}


significantly larger than those of the atoms from $390 \mathrm{~K}$ to $340 \mathrm{~K}$. Therefore, it is found that there exists the difference of the direction and the magnitude of the atomic displacement in the structural phase transitions from $390 \mathrm{~K}$ to $340 \mathrm{~K}$ and from $340 \mathrm{~K}$ to $291 \mathrm{~K}$.

\section{References}

[1] J. Fabry, V. Petricek, P. Vanek, I. Cisarova, Acta Crystallogr. B 53, 596 (1997).

[2] T. Krajewski, P. Piskunowicz, B. Mroz, Phys. Status Solidi A 135, 557 (1993).

[3] T. Krajewski, P. Piskunowicz, B. Mroz, Ferroelectrics 159, 161 (1994).

[4] J. Diaz-Hernandez, J.L. Manes, M.J. Tello, A. Lopez-Echarri, T. Breczewski, I. Ruiz-Larrea, Phys. Rev. B 53, 14097 (1996).

[5] B. Mroz, H. Kiefte, M.J. Clouter, J.A. Tuszynski, Phys. Rev. B 46, 8717 (1992).

[6] R.H. Chen, C.T. Chang, T.M. Chen, J. Phys. Chem. Solids 57, 25 (1996).

[7] M. Kaczmarski, B. Mroz, Phys. Rev. B 57, 13589 (1998).

[8] J. Fabry, T. Breczewski, V. Petricek, Acta Crystallogr. B 49, 826 (1993). 